\title{
CONTAGEM DE CÉLULAS SOMÁTICAS EM LEITE FORMAL DE PRODUTORES DE MARECHAL CÂNDIDO RONDON - PR
}

\author{
(Counting of somatic cells in milk of Marechal Cândido Rondon city \\ producers, Paraná State, Brazil) \\ BRAGA, G.C. ${ }^{1}$; BRIETZKE, A.L. ${ }^{2}$; ARAÚJO, J.S..3; GARCIA, R.C..; PEIXOTO, E.C.T.M. ${ }^{3}$ \\ ${ }^{1}$ Centro de Ciências Agrárias, Universidade Estadual do Oeste do Paraná/UNIOESTE, Cx.p.1008, Marechal \\ Cândido Rondon, PR, 85960-000, Tel. 45 3254-3216, gbraga@unioeste.br; \\ ${ }^{2}$ Acadêmico de Zootecnia, CCA / UNIOESTE, Mal. C. Rondon, PR; \\ ${ }^{3}$ Docentes do CCA / UNIOESTE, Mal. C. Rondon, PR.
}

\begin{abstract}
RESUMO - O objetivo deste trabalho foi avaliar as contagens de células somáticas (CCS) em leite cru segundo o período sazonal e o perfil produtivo de produtores da microrregião de Marechal Cândido Rondon, PR. Foram utilizados os dados da produção diária de 1580 produtores no ano de 2004. Os perfis produtivos foram estabelecidos conforme os seguintes níveis: menos de 50; entre 50 e 100; entre 100 e 250; entre 250 e 400 e mais de 400 L.dia-1. Para as avaliações com as contagens celulares foram utilizados os resultados de 934 produtores que possuíam dados completos de CCS dos 12 meses do ano, totalizando 11208 dados, os quais foram agrupados conforme os seguintes intervalos: menos que $0,4 \times 10^{6}$; de $0,4 \times 10^{6}$ a $0,75 \times 10^{6}$; de $0,75 \times 10^{6}$ a $1,0 \times 10^{6}$ e maiores de $1,0 \times 10^{6}$ CS. $\mathrm{ml}^{-1}$. Para a realização das análises estatísticas, os valores de CCS foram transformados em escore linear de células somáticas (ECS). Dos produtores amostrados, 7,9\% não atenderam à regulamentação atual para a CCS, pois apresentaram rebanhos com leite acima de $1,0 \times 10^{6} \mathrm{CS} . \mathrm{ml}^{-1}$. O aumento do perfil produtivo, em litros de leite formalizados por dia, implicou no aumento do percentual de rebanhos com contagens acima de $1,0 \times 10^{6} \mathrm{CS} \cdot \mathrm{ml}^{-1}$. Para as condições climáticas do município, o leite apresentou CCS mais elevada no verão. Dos 1580 produtores avaliados, 65\% apresentaram perfil produtivo menor que 100 litros de leite comercializados sob inspeção por dia.
\end{abstract}

Palavras-chave: sanidade; produção; sazonalidade; higiene; bovino.

ABSTRACT - The objective of this work was to evaluate the effect of the productive profile of the producers and the seasonal period on the counting of somatic cells in formal milk from Marechal Cândido Rondon city producers, in Paraná State. The productive profiles had been established with the data of the milk daily production of 1580 producers registered in cadastre of FRIMESA dairy industry in 2004, as the following intervals: less than 50; 50 and 100; 100 and 250; 250 and 400; and bigger than 400 L.day $^{-1}$. For the study of the influence of the productive profile, the following intervals of CCS had been used: less than $0,4 \times 106$;
$0,4 \times 106$ and $0,75 \times 106 ; 0,75 \times 106$ and 1,0x106; and bigger of $1,0 \times 106 \mathrm{SC} \cdot \mathrm{ml}^{-1}$. In regard to the study on the influence of the seasonal period, the values of CCS had been transformed in somatic cells scores for accomplishment of the statistical analyses. From the showed producers, $7.9 \%$ had not taken care of to the current regulation for the CCS, therefore they had presented flocks with milk above of 1,0x106 CS.ml-1. The increase of the productive profile, in liters of milk legalized per day, implied in the increase of the percentage of flocks with milk presenting counting above of $1,0 \times 106$ CS.ml-1. For the climatic conditions of the city, milk displayed greater counting of somatic cells in the summer. The majority of producers (65\%) presented productive profile less than 100 liters of legalized milk for day.

Key-words: beef cattle; health; production; seasonality; hygiene; bovine.

\section{Introdução}

O município de Marechal Cândido Rondon possui grande importância no cenário leiteiro paranaense, destacando-se como o maior produtor da Região Oeste e como o terceiro maior produtor do Estado (MEZZADRI, 2005). Em 2003, a microrregião de Toledo/ Marechal Cândido Rondon, no Oeste paranaense, destacou-se como a quarta maior produtora do país, produzindo 319 milhões de litros de leite (IBGE, 2004), decorrente, principalmente, da atividade familiar de pequenas e médias propriedades rurais, cujos perfis zootécnicos dos rebanhos são caracterizados por animais da raça holandesa (KOEHLER, 2000).

De acordo com BEM e FABRINI (2005), apenas uma parcela do leite produzido na fazenda é comercializada diretamente para as industriais, a qual caracteriza o leite formal ou inspecionado. Segundo o levantamento realizado por MEZZADRI (2005), do volume total de 545.600 .000 litros de leite produzido nas regiões paranaenses de Toledo e Cascavel, em 2000, cerca de $57,2 \%$ foram comercializados diretamente para as indústrias sob inspeção e cerca de $42.8 \%$ ficaram retidos nas propriedades ou comercializados no 
mercado informal.

O Estado do Paraná possui grande destaque no cenário leiteiro brasileiro. Segundo o IBGE, em 2004 o Paraná foi o terceiro maior produtor de leite do país com 2,395 bilhões de litros produzidos (aproximadamente 10\% da produção nacional), tendo a região Oeste como a maior produtora do Estado (IBGE, 2004).

O setor leiteiro é um dos mais importantes do agronegócio brasileiro e vem atravessando um período de evolução. As principais mudanças têm sido a implementação da nova legislação para os padrões de qualidade, o aumento nas exigências de qualidade do leite por parte das indústrias e a diferenciação do pagamento ao produtor com base na qualidade (PRATA, 1998). A adequação dos produtores a esse novo cenário tem sido a grande preocupação voltada na sustentabilidade da atividade leiteira, principalmente em nível da produção rural familiar.

A contagem de células somáticas (CCS) no leite tem sido considerada como um dos principais critérios de qualidade, pois está correlacionada com a composição, com o rendimento industrial e com a segurança alimentar. Para os produtores a CCS do leite indica a sanidade das glândulas mamárias das vacas, podendo sinalizar para perdas significativas de produção e alterações da qualidade do leite (HARMON, 1994; SANTOS, 2002; BUENO et al., 2005).

As células somáticas são, normalmente, células de defesa (leucócitos) do organismo que migram do sangue para o interior da glândula mamária com o objetivo de combater agentes infecciosos, mas podem ser também células secretoras descamadas (HARMON, 1994; MACHADO et al., 1999; SHALLIBAUM, 2001).

$A$ atividade infecciosa de microrganismos no interior da glândula mamária estimula a migração de leucócitos aumentando, dessa maneira, a CCS do leite. Assim, a CCS no leite do tanque de resfriamento é uma ferramenta valiosa na avaliação do nível de mastite subclínica no rebanho (HARMON, 2001; SHALLIBAUM, 2001; MACHADO et al., 2000).

Segundo VIANA (2000) e OSTRENSKY (1999), além da presença de infecções intramamárias (mastites) e fatores intrínsecos como raça e estágio de lactação, outros fatores extrínsecos podem interferir na CCS como a época do ano, estresse climático, entre outros.

Segundo RYSANEK e BABAK (2005), recentemente a CCS do leite tem sido empregada como critério de pagamento por qualidade do leite, o que a torna uma ferramenta de gestão e monitoramento da qualidade e tem cada vez mais espaço dentro da propriedade leiteira, pois está diretamente relacionada com programas de redução de perdas de produção e oportunidades de maior remuneração do leite.

Neste contexto, o objetivo deste trabalho foi avaliar a influência do perfil produtivo e do período sazonal sobre as contagens de células somáticas em leite formal de produtores da microrregião de Marechal Cândido Rondon, PR.

\section{Material e Método}

Este estudo foi realizado pelo Centro de Ciências Agrárias da UNIOESTE, Campus de Marechal Cândido Rondon, PR, com a parceria do Laticínio FRIMESA que cedeu os dados de contagens de células somáticas (CCS) e volume de leite recebido diariamente, por produtor, durante o ano de 2004, num total de 1580 produtores da microrregião de Marechal Cândido Rondon.

Com base nas informações do volume de leite recebido pelo laticínio, de cada produtor, determinou-se o perfil produtivo dos produtores conforme os seguintes níveis: menos de 50; entre 50 e 100; entre 100 e 250; entre 250 e 400 e mais de 400 litros de leite por dia.

Para as análises com a CCS foram utilizados os resultados de 934 produtores que possuíam dados completos de contagens celulares dos 12 meses do ano, totalizando 11208 dados. Neste caso, as amostragens de leite foram realizadas mensalmente em cada propriedade e foram acondicionadas em frascos plásticos padronizados de $40 \mathrm{ml} \mathrm{com}$ adição do conservante bronopol (2-bromo-2-nitropropano-1,3-diol). As amostras foram enviadas para análises de CCS no Laboratório Centralizado de Análise da Qualidade do Leite, em Curitiba, através do convênio entre a Associação Paranaense de Bovinos da Raça Holandesa e Universidade Federal do Paraná.

Determinou-se a relação entre o perfil produtivo, o número e a porcentagem de produtores com as contagens celulares em diferentes intervalos que foram estabelecidos com base na regulamentação oficial (BRASIL, 2002), sendo esses intervalos os seguintes: contagens menores que $0,4 \times 10^{6}$; de $0,4 \times 10^{6}$ a $0,75 \times 10^{6}$; de $0,75 \times 10^{6}$ a $1,0 \times 10^{6}$; e maiores que $1,0 \times 10^{6} \mathrm{CS}$. $\mathrm{ml}^{-1}$. Determinou-se também a influência do período sazonal sobre a CCS considerando as quatro estações do ano: inverno; primavera; verão e outono. Para a realização das análises estatísticas a CCS foi transformada em Escore Linear de Células Somáticas (ECS) conforme a seguinte equação (DABDOUTB e SHOOK, 1984):

$$
E C S=\log _{2}\left(\frac{C C S}{100.000}\right)+3
$$

A contagem de células somáticas se baseou no método de medição direta, realizada através de citometria de fluxo, utilizando o equipamento SOMACOUNT 500. Aos resultados foi aplicada Análise de Variância, teste Tukey de comparação entre médias e descrição do Desvio Padrão. O nível de confiança considerado foi de $95 \%$.

\section{Resultados e Discussão}

Conforme a TABELA 1, aproximadamente $65 \%$ dos produtores de leite comercializaram abaixo de $100 \mathrm{~L} . d i a^{-1}$, sendo que desses produtores, $38,92 \%$ comercializaram abaixo de 50 L.dia $^{-1}$, com média de 28,7 L.dia ${ }^{-1}$, que 
caracterizaram os pequenos e micro-produtores do município. Por outro lado, a parcela dos maiores produtores com perfis produtivos acima de 400 L.dia $^{-1}$ foi de apenas $3,42 \%$.

Com base nesses dados e considerando o número representativo de produtores amostrados, constatou-se que o perfil produtivo predominante do município pode ser caracterizado por pequenos e micro produtores de leite. Neste sentido, ressalta-se que em 2004 o município possuía aproximadamente 2100 produtores de leite, segundo informações cedidas pela Associação Leite Oeste de Marechal Cândido Rondon.

TABELA 1 - PERFIL PRODUTIVO DE LEITE FORMAL DE PRODUTORES DO MUNICÍPIO DE MARECHAL CÂNDIDO RONDON, PR, DE ACORDO COM A PRODUÇÃO MÉDIA DIÁRIA. MARECHAL C. RONDON, 2004.

\begin{tabular}{|c|c|c|c|c|c|}
\hline \multicolumn{3}{|c|}{ Perfil produtivo (L.dia ${ }^{-1}$ ) } & \multirow[b]{2}{*}{$\begin{array}{c}\mathrm{N}^{\mathrm{o}} \mathrm{de} \\
\text { produtores }\end{array}$} & \multirow[b]{2}{*}{$\begin{array}{c}\text { Percentual relativo } \\
\%\end{array}$} & \multirow[b]{2}{*}{$\begin{array}{c}\text { Produção média } \\
\left(\text { L.dia }^{-1}\right)\end{array}$} \\
\hline Níveis & Média & $\begin{array}{l}\text { Desvio } \\
\text { padrão }\end{array}$ & & & \\
\hline$<50$ & 28,7 & 12,3 & 615 & 38,92 & 17.651 \\
\hline $50<100$ & 71,2 & 14,2 & 402 & 25,44 & 28.622 \\
\hline $100<250$ & 156,1 & 41,9 & 410 & 25,95 & 64.001 \\
\hline $250<400$ & 320,8 & 44,0 & 99 & 6,27 & 31.759 \\
\hline$>400$ & 623,3 & 211,8 & 54 & 3,42 & 33.658 \\
\hline Total & & & 1580 & 100 & 175.691 \\
\hline
\end{tabular}

A TABELA 2 mostra que 7,9\% dos produtores não atenderam à regulamentação atual para o critério legal de CCS do leite (BRASIL, 2002), os quais apresentaram rebanhos cujos leites possuíam contagens acima de $1 \times 10^{6} \mathrm{CS} . \mathrm{ml}^{-1}$. Para esse grupo de produtores, o aumento do nível do perfil produtivo acarretou em aumento do percentual de produtores com ocorrências de CCS acima de $1 \times 10^{6} \mathrm{CS} . \mathrm{ml}^{-1}$, ou seja, para o perfil produtivo com menos de 50 L.dia $^{-1}, 6 \%$ dos produtores estavam acima do critério legal, enquanto para o perfil produtivo com mais de 400 L.dia ${ }^{-1}$, foram 9,5\% dos produtores com contagens acima de $1 \times 10^{6} \mathrm{CS} . \mathrm{ml}^{-1}$.

Vale ressaltar que o limite legal atual brasileiro para CCS do leite em tanque de resfriamento, segundo a Instrução Normativa $n^{\circ} 51$ do MAPA, para a Região Sul, é de $1 \times 10^{6} \mathrm{CS} \cdot \mathrm{ml}^{-1}$ (BRASIL, 2002), que ainda é muito elevado para um padrão de qualidade adequado do leite. Esta nova regulamentação prevê a redução progressiva deste limite nos próximos anos até atingir $0,4 \times 10^{6}$ CS.ml-1, aproximando-se aos padrões internacionais.

Analogamente, a TABELA 2 mostra também que para o intervalo de contagens menores que $400 \times 10^{3}$ CS. $\mathrm{ml}^{-1}$, a diminuição do perfil produtivo implicou no aumento do percentual de produtores com rebanhos produzindo leite nessas condições de baixa CCS. É importante verificar também, que a grande maioria dos produtores, ou seja, $65,1 \%$ (resultado da soma dos três últimos intervalos de CCS) dos produtores analisados apresentaram leite com CCS acima de $400 \times 10^{3} \mathrm{CS}_{\mathrm{ml}}{ }^{-1}$, ou seja, estão acima das metas brasileiras que é a de se adequar aos padrões internacionais que, segundo ZANELA et al. (2006), as exigências legais dos principais países produtores e exportadores estão entre 400 e $500 \times 10^{3} \mathrm{CS} \cdot \mathrm{ml}^{-1}$.

TABELA 2 - NÚMERO E PORCENTAGEM DE PRODUTORES PARA OS DIFERENTES INTERVALOS DE CONTAGENS DE CÉLULAS SOMÁTICAS (CCS) E PERFIS PRODUTIVOS. MARECHAL C. RONDON, 2004.

\begin{tabular}{cccccc}
\hline Perfil & No de & \multicolumn{4}{c}{ Intervalos de CCS $\left(\times 10^{3}{\left.\mathrm{CS} . \mathrm{ml}^{-1}\right)}^{-1}\right.$} \\
\cline { 2 - 6 } $\left.\begin{array}{c}\text { produtivo } \\
(\text { L.dia }\end{array}{ }^{-1}\right)$ & $\begin{array}{c}\text { produtores } \\
\text { avaliados }\end{array}$ & $<400$ & $>400$ & $>750$ & $>1.000$ \\
\hline$<50$ & 281 & $110(39,1 \%)$ & $114(40,6 \%)$ & $40(14,2 \%)$ & $17(6,0 \%)$ \\
$50<100$ & 257 & $97(37,7 \%)$ & $117(45,5 \%)$ & $26(10,1 \%)$ & $17(6,6 \%)$ \\
$100<250$ & 287 & $93(32,4 \%)$ & $132(46,0 \%)$ & $37(12,9 \%)$ & $25(8,7 \%)$ \\
$250<400$ & 67 & $18(26,9 \%)$ & $25(37,3 \%)$ & $13(19,4 \%)$ & $11(16,4 \%)$ \\
$>400$ & 42 & $8(19,0 \%)$ & $25(59,5 \%)$ & $5(11,9 \%)$ & $4(9,5 \%)$ \\
\hline Total & 934 & $326(34,9 \%)$ & $413(44,2 \%)$ & $121(13,0 \%)$ & $74(7,9 \%)$ \\
\hline
\end{tabular}


Segundo a TABELA 3, a menor média de CCS $\left(527,6 \times 10^{3} \mathrm{CS} . \mathrm{ml}^{-1}\right)$ ocorreu para os produtores com perfil produtivo abaixo de $50 \mathrm{~L}^{-d i a}{ }^{-1}$ e a maior $\left(696,7 \times 10^{3}\right.$ CS. $\mathrm{ml}^{-1}$ ) foi dos produtores com perfil entre 250 e 400 L.dia $^{-1}$. Esses valores estão ligeiramente superiores aos encontrados por MACHADO et al. (2000), PAULA et al. (2004) e BUENO et al. (2005), os quais registraram, respectivamente, médias amostrais de $505 \times 10^{3} \mathrm{CS}_{\mathrm{ml}}{ }^{-1}$ em rebanhos de São Paulo e do Sul de Minas Gerais, $486,8 \times 10^{3} \mathrm{CS} . \mathrm{ml}^{-1}$ em Santa Catarina, Paraná e São Paulo e $347 \times 10^{3} \mathrm{CS} . \mathrm{ml}^{-1}$ em Goias.

A TABELA 3 mostra que o inverno, marcado pelo período com temperaturas mais baixas, quando comumente há ocorrências de temperaturas negativas na Região de Marechal C.
Rondon, contribuiu para os menores índices de CCS e também foi o período de menores desvios padrão, ou seja, de menor variabilidade de resultados. OSTRENSKY (1999) obteve resultados semelhantes, relatando que as maiores médias de CCS no Paraná ocorreram nos meses mais quentes compreendidos entre janeiro e fevereiro. A mesma correlação entre temperatura e CCS foi constatada também por BUENO et al. (2005). Vale ressaltar que segundo KOEHLER (2000), o Clima Mesotérmico predomina em praticamente toda a região Oeste do Paraná, cujos invernos são rigorosos, com ocorrência de geadas e incidência média de chuvas e os verões são chuvosos com temperaturas bem elevadas.

TABELA 3 - CONTAGEM DE CÉLULAS SOMÁTICAS E DESVIO PADRÃO PARA O LEITE FORMAL EM FUNÇÃO DOS PERFIS PRODUTIVOS E DO PERÍODO SAZONAL. MARECHAL C. RONDON, 2004.

\begin{tabular}{|c|c|c|c|c|c|c|c|c|c|c|}
\hline \multirow{3}{*}{$\begin{array}{l}\text { Período } \\
\text { sazonal }\end{array}$} & \multicolumn{10}{|c|}{ Perfis produtivos, em L.dia ${ }^{-1}$} \\
\hline & \multicolumn{2}{|c|}{$<50$} & \multicolumn{2}{|c|}{$50<100$} & \multicolumn{2}{|c|}{$100<250$} & \multicolumn{2}{|c|}{$250<400$} & \multicolumn{2}{|c|}{$>400$} \\
\hline & $\bar{M}$ & DP & $\mathrm{M}$ & DP & $\mathrm{M}$ & DP & $\mathrm{M}$ & $\mathrm{DP}$ & $\mathrm{M}$ & DP \\
\hline Primavera & $\underset{*}{542,2}$ & $\underset{*}{481,6}$ & $\begin{array}{c}518, \\
1\end{array}$ & 433 & 571,4 & $\begin{array}{c}444, \\
3\end{array}$ & $\begin{array}{c}694, \\
0\end{array}$ & $\begin{array}{c}319, \\
1\end{array}$ & $\begin{array}{c}545, \\
1\end{array}$ & 224,3 \\
\hline Verão & 589,3 & 477,5 & $\begin{array}{c}574 \\
0\end{array}$ & 385,8 & 618,5 & $\begin{array}{c}406, \\
0\end{array}$ & $\begin{array}{c}784, \\
2\end{array}$ & $\begin{array}{c}472, \\
6\end{array}$ & $\begin{array}{c}680 \\
4\end{array}$ & 303,5 \\
\hline Outono & 499,5 & 390,7 & $\begin{array}{c}549 \\
4\end{array}$ & 422 & 611,1 & $\begin{array}{c}457, \\
3\end{array}$ & $\begin{array}{c}798, \\
6\end{array}$ & $\begin{array}{c}697, \\
0\end{array}$ & $\begin{array}{c}667 \\
2\end{array}$ & 477,8 \\
\hline Inverno & 479,3 & 327 & $\begin{array}{c}473, \\
8\end{array}$ & 339,2 & 502,3 & 368 & $\begin{array}{c}509, \\
8\end{array}$ & $\begin{array}{c}260, \\
1\end{array}$ & $\begin{array}{c}483 \\
7\end{array}$ & 231,4 \\
\hline Total & 527,6 & 419,2 & $\begin{array}{c}528 \\
8\end{array}$ & 395,0 & 575,8 & $\begin{array}{c}418, \\
9\end{array}$ & $\begin{array}{c}696, \\
7\end{array}$ & $\begin{array}{c}437, \\
2\end{array}$ & $\begin{array}{c}594, \\
1\end{array}$ & 309,3 \\
\hline
\end{tabular}

$\mathrm{M}=$ Média aritmética; $\mathrm{DP}=$ Desvio padrão

*: CS. $\mathrm{ml}^{-1} \times 10^{3}$

Os altos níveis de desvio padrão verificados na TABELA 3 indicam que existem grandes variações de CCS do leite entre os rebanhos analisados. Altas variações também foram encontradas por MACHADO (2000) e PAULA, et al. (2004). Essas altas variações, associadas aos altos níveis de CCS verificados, são indicativas para a necessidade de maiores investimentos e atuação da assistência técnica para o controle da mastite nos rebanhos e melhoria da qualidade do leite do município. Para os produtores com perfil maior que $400 \mathrm{~L} . d i a^{-1}$, os baixos desvios padrão constatados na TABELA 3 podem ser explicados devido ao menor número de produtores amostrados para esta categoria.

Com base na TABELA 4, constatou-se que o ECS do leite em todos os níveis de perfis produtivos foi significativamente influenciado pelo período sazonal, concluindo-se que as temperaturas mais elevadas do verão foram responsáveis pelos ECS mais elevados do leite dos rebanhos. Esses resultados concordam com HARMON (1994) e BUENO et al., (2005), os quais obtiveram resultados de correlação positiva entre temperatura ambiente e ECS do leite. 
TABELA 4 - ESCORE DE CÉLULAS SOMÁTICAS (ECS) DO LEITE FORMAL SEGUNDO O PERFIL PRODUTIVO E O PERÍODO SAZONAL E TESTE TUKEY. MARECHAL C. RONDON, 2004.

\begin{tabular}{|c|c|c|c|c|c|c|c|}
\hline \multirow{2}{*}{$\begin{array}{l}\text { Período } \\
\text { sazonal }\end{array}$} & \multicolumn{5}{|c|}{ Perfis produtivos (em L.dia ${ }^{-1}$ ) } & \multicolumn{2}{|c|}{ Total } \\
\hline & $<50$ & $50<100$ & $100<250$ & $250<400$ & $>400$ & $\bar{M}$ & $\mathrm{DP}$ \\
\hline Primavera & $5,06 a b$ & $5,03 a b$ & $5,19 a b$ & $5,36 a b$ & $5,33 a b$ & $5,19 a b$ & 0,87 \\
\hline Verão & $5,20 a$ & $5,23 a$ & $5,34 \mathrm{a}$ & $5,73 \mathrm{a}$ & $5,61 \mathrm{a}$ & 5,42 a & 0,90 \\
\hline Outono & $4,95 \mathrm{~b}$ & $5,14 \mathrm{ab}$ & $5,29 a$ & $5,64 \mathrm{a}$ & $5,48 a b$ & 5,30 a & 0,96 \\
\hline Inverno & $4,85 \mathrm{~b}$ & $4,96 \mathrm{~b}$ & $5,05 \quad b$ & $5,15 \quad b$ & $5,11 \quad b$ & $5,02 \quad b$ & 0,87 \\
\hline $\begin{array}{c}\text { № de } \\
\text { produtores }\end{array}$ & 281 & 257 & 287 & 67 & 42 & & \\
\hline
\end{tabular}

Médias seguidas pela mesma letra, na vertical, não diferem em nível de 5\% de significância pelo teste Tukey. $\mathrm{M}=$ Média aritmética; DP= Desvio padrão.

\section{Conclusões}

Concluiu-se que dos produtores amostrados, 7,9\% não atenderam à regulamentação atual para a CCS, pois apresentaram rebanhos com leite acima de $1,0 \times 10^{6}$ CS. $\mathrm{ml}^{-1}$. O aumento do perfil produtivo, em litros de leite formalizados por dia, implicou no aumento do percentual de rebanhos com contagens no leite acima de $1,0 \times 10^{6}$ CS. $\mathrm{ml}^{-1}$. Para as condições climáticas do município, o leite apresentou CCS mais elevada no verão. Dos 1580 produtores avaliados da microrregião de Marechal Cândido Rondon, 65\% apresentaram perfil produtivo menor que 100 litros de leite comercializados sob inspeção (formalizados) por dia.

\section{Agradecimentos}

Ao Laticínio FRIMESA, pela concessão do banco de dados e pelo apoio que possibilitou o desenvolvimento deste estudo.

\section{Referências}

BEM, A; FABRINI, J.E. A comercialização informal de leite como componente de resistência camponesa em Marechal Cândido Rondon - PR. Nera, a.8, n.6, p.14-26, 2005.

BRASIL. Instrução Normativa n.51 de 18 de setembro de 2002. Dispõe sobre regulamentos técnicos aplicados ao leite cru e pasteurizado. Diário Oficial da União, Brasília, 20 set. 2002. Seção 1, n.183, p.13-22.

BUENO, V.F.F.; MESQUITA, A.J.; NICOLAU, E.S.; OLIVEIRA, A.N.; OLIVEIRA, J.P.; NEVES, R.B.S.; MANSUR, J.R.G.; THOMAZ, L.W. Contagem celular somática: relação com a composição centesimal do leite e período do ano no Estado de Goiás. Ciência Rural, v.35, n.4, p.848-854, 2005.

DABDOUTB, S.A.M.; SHOOK, G.E. Phenotypic relations among milk yield, somatic cell count, and clinical mastitis. Journal of Dairy Science, v.67, n.1, p.163- 164, 1984. (Supplement 1).

HARMON, R. J. Physiology of mastitis and factors affecting somatic cell counts. Journal of Dairy Science, v.77, n.7, p.2103-2112, 1994.
HARMON, R. J. Somatic cells counts: a primer. In: ANNUAL MEETING NATIONAL MASTITIS COUNCIL, 40, Reno, 2001. Proceedings. Madison, National Mastisti Council, 2001, p.3-9.

IBGE. Instituto Brasileiro de Geografia e Estatística. Produção da Pecuária Municipal, Rio de Janeiro: MPOG, v. 32, 2004.

KOEHLER, J.C. Cenário da produção de leite no Oeste do Paraná. Curitiba: SEAB/DERAL, 2000.

MACHADO, P.F.; PEREIRA, A.R.; SARRÍES, G.A. Efeitos da contagem de células somáticas na qualidade do leite e a atual situação de rebanhos brasileiros. Revista do Instituto de Laticínios "Cândido Tostes", v.54, n.309, p.10-16, 1999.

MACHADO, P.F.; PEREIRA, A.R.; SARRÍES, G.A. Composição do leite de tanques de rebanhos brasileiros distribuídos segundo sua contagem de células somáticas. Revista Brasileira de Zootecnia, v.29, n.6, p.1883-1886, 2000.

MEZZADRI, F.P. Panorama da pecuária leiteira: aspectos internacionais, nacionais e estaduais, Curitiba: SEAB/DERAL, 2005.

OSTRENSKY, A. Efeitos de ambiente sobre a contagem de células somáticas no leite de vacas da raça holandesa no Paraná. Curitiba, 1999, 114p. Dissertação (Mestrado em Ciências Veterinárias), Curso de Medicina Veterinária, Universidade Federal do Paraná.

PAULA, M.C.; RIBAS, N.P.; MONARDES, H.G.; ARCE, J.E.; ANDRADE, U.V.C. Contagem de Células Somáticas em Amostras de Leite. Revista Brasileira de Zootecnia, v.33, n.5, p.1303-1308, 2004.

PRATA, L. F. Fundamentos de Ciência do Leite. São Paulo: Unesp, 1998, 119p.

RYSANEK, D; BABAK, V. Bulk tank milk somatic cell count as an indicator of the hygiene status of primary milk production. Journal of Dairy Research, v.72, p.1-6, 2005.

SANTOS, M.V. Efeito da mastite sobre a qualidade do leite e dos derivados lácteos. In: CONGRESSO PANAMERICADO DE QUALIDADE DO LEITE E CONTROLE DE MASTITE, II. 2002, Ribeirão Preto, Anais.... São Paulo: Instituto Fernando Costa, 2002, p.179-188. 
SCHALLIBAUM, M. Impact of SCC on the quality of fluid milk and cheese. In: ANNUAL MEETING NATIONAL MASTITIS COUNCIL, 40, Reno, 2001. Proceedings. Madison, National Mastisti Council, 2001, p.38-46.

VIANA, L. C. Duração das infecções naturais por estafilococos coagulase negativos e contagem de células somáticas em vacas primíparas. Londrina,
2000. Dissertação (Mestrado em Sanidade Animal), Universidade Estadual de Londrina.

ZANELA, M.B.; FISCHER, V.; RIBEIRO, M.E.R.R.; STUMPF JR, W; ZANELA, C.; MARQUES, L.T.; MARTINS, P.R.G. Qualidade do leite em sistemas de produção na região Sul do Rio Grande do Sul. Pesquisa Agropecuária Brasileira, v.41, n.1, p.153-159, 2006.

Recebido para publicação: $\quad$ 16/10/2006 Aprovado:
$21 / 12 / 2006$ 